УДК 1:3; 001.8:3

DOI 10.25205/2541-7517-2018-16-4-216-226

\title{
В. В. Самсонов
}

Институт философии и права СО РАН

ул. Николаева, 8, Новосибирск, 630090, Россия

highbook@yandex.ru

\section{ИНСТИТУЦИОНАЛЬНЫЕ И СОЦИОКУЛЬТУРНЫЕ ФАКТОРЫ ПОСТСОЦИАЛИСТИЧЕСКИХ ТРАНСФОРМАЦИЙ}

\begin{abstract}
Исследуется логика развития теории постсоциалистического транзита под влиянием практики преобразований в различных странах бывшего «соцлагеря», показавшей необходимость выработки более дифференцированной доктрины, а также проблема соотношения институциональных и социокультурных факторов преобразований. Если в современных исследованиях причин path dependency авторы все чаще обращают внимание на культурологические факторы, то практический анализ развития постсоциалистических обществ в контексте важнейших институциональных изменений демонстрирует удивительную динамику, выступающую скорее рационально-реактивным ответом на сиюминутные изменения в институциональных условиях. Это дает основания предположить, что институты определяют выбор траектории развития (на индивидуальном уровне - смену адаптационных, жизненных стратегий), а устойчивой «колеей» ее делает культура.

Ключевые слова: трансформация, постсоциалистический транзит, институциональные и социокультурные факторы, экономические реформы.
\end{abstract}

Радикальные преобразования в постсоциалистических странах, начавшиеся в конце 80-х гг. XX в., актуализировали проблему транзита социальных систем, его направлений и вариаций, а также вопросы механизма, факторов, да и самой возможности преобразования одного общества в типологически другое путем простого копирования институционального устройства стран-«моделей» (их импорта в совершенно иной культурный контекст). Эти вопросы имеют не только теоретическое значение, поскольку следование простейшей (неолиберальной) схеме транзита привело большую часть реформируемых 
государств к глубокому социально-экономическому кризису, углубляемому существенной деформацией новых рыночно-демократических институтов под воздействием неформальных практик, обусловивших их крен в «серую зону». При механических заимствованиях технологий и институтов не учитывается, что импортируемые институты - результат длительного эволюционного развития, а попытка «привить» их к реалиям общества, находящегося на ином, возможно, параллельном, пути эволюционного развития, - изначально чревата проблемой совместимости новых институтов и укоренившихся ценностей, обычаев, норм поведения и т. п. Поэтому имплантируемые из другой социальной реальности формы жизнеустройства на новой почве дают совсем иной эффект, нежели тот, на который рассчитывали реформаторы.

В данной работе исследуется логика развития теории постсоциалистического транзита под влиянием практики преобразований в различных странах бывшего «соцлагеря», показавшей необходимость выработки более дифференцированной доктрины, а также проблема соотношения институциональных и социокультурных факторов преобразований, решение которой требует отказа от одномерных транзитологических концепций в сторону более сложных, способных учесть те противоречия и парадоксы, которые открываются исследователям изменений в реформируемых обществах.

Доминирующая доктрина перехода первоначально применяла однородный анализ и стратегию к большинству национальных случаев (за исключением азиатских стран), подразумевая под транзитом механистическое и детерминированное представление о движении от одной точки равновесия к другой. Первоначальные обобщения о «транзите вообще», как правило, основывались на опыте одной или нескольких «типичных» стран, которые считаются «типичными», но выводы аналитиков опровергались другими примерами реформирования. Чтобы извлечь «общие уроки» из процессов трансформации, необходимо обратиться к проблеме разнообразия. В противном случае мы сталкиваемся с риском ошибочной генерализации одного специфического или частного опыта без понимания исторической и культурной специфики как необходимого компонента общей теоретизации.

В ходе постсоциалистического транзита первоначально основное внимание уделялось институциональному реформированию сфер политики и экономики («двойной транзит»), путем принятия новых (официальных) норм. Институциональная имитация западных обществ поддерживалась влиянием международных организаций, 
таких как Международный валютный фонд (с его требованиями выполнения «условий» для получения инвестиций и помощи), и ставила своей целью определенную конвергенцию или, по крайней мере, приближение к институциональным и организационным конфигурациям, характерным для западных социально-экономических систем. До середины 1990-х гг. исследователи постсоциалистического транзита почти полностью игнорировали вопрос государствостроительства и национальный вопрос, поскольку использовались наработки, полученные на осмыслении опыта реформирования латиноамериканских стран и государств Южной Европы, где транзит имел место в устоявшихся государствах, с устоявшимися институтами частной собственности и рыночной экономики [Kuzio, 2001].

Однако опыт первых лет реформирования постсоциалистических государств показал, что без формирования и укрепления государственных институтов власти невозможно обеспечить такие существенные общественные блага, как личная безопасность, правосудие, а также юридическое равенство как важнейший элемент всех жизнеспособных институтов. В этом смысле имеется важное различие между уходом государства из экономики, уменьшением его веса в общественно-политической жизни и его неспособностью обеспечивать указанные общественные блага. Признание этого факта приводит исследователей к заключению о том, что «проблемы государственности должны переместиться в центр внимания политических деятелей и теоретиков» [Linz, Stepan, 1996. Р. 366]. Например, Украина и Белоруссия с обретением независимости столкнулись с необходимостью не только реформирования экономики и политики но также с проблемами создания властных институтов и строительства национального государства.

C добавлением исследователями государствостроительства к структуре постсоциалистического транзита он стал «тройным переходом», в отличие от «двойного транзита», который пережили пост-авторитарные государства Южной Европы и Латинской Америки. Некоторые исследователи объединяют четыре аспекта транзита в две широкие области - демократия / рынок и нацие / государствостроительство [Hall, 1996]. Еще одно важное направление постсоциалистического перехода связано со сферой национального строительства, трактуемого как масштабные реальные социальные изменения, выражающиеся в изменении массовых стратегий социального поведения, детерминированных сменой ценностных установок, индивидуальных и массовых идентификаций, обусловленных заменой свойственного социализму принципа интернационализма на принцип 
национального самоопределения и государственного суверенитета. В современном понимании национальное строительство означает, прежде всего, не акцентирование этнических интересов, а консолидацию нескольких видов объективных отношений (экономических, политических, языковых, культурных, религиозных, исторических) и их субъективного отражения в коллективном сознании, а наблюдаемое возрождение национального самосознания следует интерпретировать в рамках мобилизационного подхода, в соответствии с которым национальная идентичность, обладающая значительным солидаристическим потенциалом, усиливается, в то время как другие мобилизационные модели ослабевают.

Добавление в структуру постсоциалистического транзита проблематики нациестроительства позволяет говорить о четырехчастной структуре социального кризиса постсоветских обществ.

Национальные траектории изменений совмещают в себе элементы конвергенции, дивергенции и воспроизводящихся различий. Сложное сочетание различных тенденций и факторов определяет как сходство социальных процессов в реформируемых странах бывшего социалистического лагеря, так и их вариативность.

К группе конвергентных факторов (факторов сходства) следует отнести: институциональное подражание Западу (имитация, импорт институтов западных обществ), общие черты в экономике, в традициях и технологиях управления, а также тенденции глобализации и влияние международных организаций (Международный валютный фонд и т. п.) и их требований. Общие тенденции развития реформируемых обществ могут быть обобщены тремя характеристиками: общее (постсоциалистическое) наследие, подражание западным странам (в том числе направленность на интеграцию в ЕС и другие структуры) и влияние международных организаций. Общее наследие проявляется в следующем: 1) значительный удельный вес общественного сектора; 2) разнообразие институциональных форм собственности; 3 ) большая значимость неформальных норм и социальных сетей разного рода; 4) сократившийся, но не исчезнувший вовсе патернализм государства.

К факторам вариативности относятся: разнообразие начальных условий, как следствие различающегося опыта развития при социализме, различие национальных траекторий реформирования (уникальные политические, социально-экономические, социокультурные условия: национальная «зависимость пути»), разнообразие внешних институциональных влияний, особенности адаптации импортируемых институтов (в соответствии с национальным, социальным 
и культурным контекстом), развитость государственных институтов и их инфраструктуры, определяемая фактическим статусом реформируемых государств в административно-политических системах союзных государств и социалистической системе в целом, уровень и качество национальной консолидации (различие в стратегиях и практиках нациестроительства).

Первая группа общих тенденций обусловливает движение реформируемых государств к группе западных капиталистических экономик (в большинстве случаев - к их европейской подгруппе). Вторая часть конвергентных тенденций, связанных с постсоциалистическим наследием (а также с до-социалистической историей), обусловливает воспроизводство разрыва между реальным состоянием дел и целью преобразований. Наконец, фактор зависимости «от предшествующего пути» развития играет важную роль формировании весьма различающихся и устойчивых траекторий институциональных изменений, которые не могут быть сведены к простой конвергенции, ни к дивергенции [Stark, 1992].

Самая важная проблема «реформирования сверху» заключается в соответствии нового институционального порядка внешним условиям, что, в свою очередь, предполагает обращение к проблеме влияния культуры и предшествующих форм институциональной организации на современные процессы преобразований, получившей в неоинституционализме концептуализацию в понятии path dependency (зависимость от первоначально выбранного пути, эффект колеи). Общая сущность такого представления заключается в том, что развитие любой детерминированной системы будет определяться начальными условиями и законом движения (динамическими соотношениями). На процесс становления демократических институтов и гражданского общества в странах бывшего «соцлагеря» неизбежно должны были оказывать влияние исторически предшествующие институциональные формы управления, а также традиции, значимые для управленческих и социально-политических взаимодействий (преемственность политической культуры и представлений о власти и политике).

В современных исследованиях причин path dependency авторы все чаще обращают внимание на культурологические факторы - ментальность, образование, традиции, обычаи, что иногда может послужить поводом для обвинения в культурном редукционизме и сверхконцептуализации изучаемых феноменов. Так, неоинституционалист С. Пейович пишет, что «культура коллективизма и эгалитаризма в Центральной и Восточной Европе тем более сильна, чем далее 
на восток и юго-восток продвинется путешественник... Культурные различия региона объясняют и различия в результатах транзита» [Pejovich, 2003. Р. 351]. Культурологические теории иногда являются тавтологическими. Отсталость Японии с точки зрения капиталистического развития в течение длительного времени приписывалась конфуцианской культуре (например, Вебером). Однако позже та же самая культура была призвана объяснить успехи Японии в капиталистическом развитии. Также культурологический подход иногда используется, чтобы объяснить как «случай» Северной Кореи («культура риса», традиции «большой семьи»), так и вестернизацию Южной Кореи - т. е. вариативность в развитии одного народа с древней единой культурой.

Поскольку особенности в ходе реформ связываются с факторами, воспринимаемыми преимущественно как культурно обусловленные и поэтому относительно стабильные, медленно эволюционирующие (если вообще изменяющиеся), культура становится важной, но внешней (экзогенной) переменной. Как отмечает М. Грановеттер, отсутствие ясно выраженного динамического аргумента приводит к тому, что институционализм «не знает готовых способов объяснения институтов как порождения индивидуального действия и таким образом возвращается к подходам, основанным на общих чертах окружающей среды» [2004. С. 79].

Логичным следствием «культурного подхода» является переход от предметной области институциональной экономики к сфере социальной философии и антропологии, к анализу логики действий неформальных акторов в категориях «этоса», ценностно-этической обусловленности социального действия. Рассматриваемый с такой точки зрения российский сельский социум (в котором неформальное регулирование в период реформ оказалось более значимым, чем формальное) представляется воплощением неустранимых в процессе развития общества социально-организационных принципов (или, как принято говорить сегодня - определенной «матрицы»). Очевидно, что признание культурной обусловленности массовых неформальных практик ведет к архаизации явления, а теоретический и практический инструментарий исследований оказывается одинаков для изучения обществ, находящихся на разных стадиях развития, например неформальных практик восточноевропейских крестьян и социальных норм общинной экономики земледельцев Нигерии. Основной же недостаток социокультурной трактовки явления заключается в том, что она уделяет недостаточное внимание адаптивно-реактивному характеру динамики развития институтов и практик. Воспри- 
нимая адаптационные реакции индивидуумов и социальных групп как оформленные и устойчивые явления (к тому же иногда связывая и обобщая их с феноменами, существовавшими в совершенно иных условиях), социокультурный подход к объяснению неформальной экономики вводит ряд новых концептуальных дихотомий (например, традиционности / инновационности, отсталости / развития и т. п.), что задает иногда совершенно излишние контексты для анализа. Таким образом, складывается устойчивая тенденция «сверхконцептуализации» феномена. Критикуя излишнюю увлеченность объяснения экономического или социального поведения условиями среды (например, культурными паттернами), М. Грановеттер справедливо замечает, что исследователи неформальных институтов придерживаются крайних позиций, от «недосоциализированного» понятия рационального, максимизирующего выгоду индивидуума, до «сверхсоциализированных» концепций индивидуумов, послушных правилам и культурному диктату.

Анализ развития российского сельского неформального сектора в контексте важнейших институциональных изменений в стране показывает, что процессы и явления, основания которых исследователи пытаются обычно связать с традиционной культурой (крестьянства), - демонстрируют удивительную динамику, выступающую скорее рационально-реактивным ответом на сиюминутные институциональные условия деятельности.

Важнейшей особенностью процессов самоорганизации сельских сообществ России в 1990-е гг. являются усиление роли неформальных взаимодействий и неформальный характер большинства вновь сформированных интегративных институтов и структур. Неформальный сектор существовал и в советский период, но в годы реформ субъектами неформальных практик стали выступать практически все основные акторы и структуры сельского социума - от простых жителей села, сельских домохозяйств и реформированных колхозов и совхозов - до органов местного самоуправления и бюджетных, государственных и муниципальных структур, школ и больниц (т. е. и субъектов формальной сферы), а экономика ЛПХ превратилась в один из крупнейших сегментов аграрной отрасли.

Анализ современных тенденций социально-экономического развития российского села показывает сокращение значения всех основных структур, генерирующих неформальные связи и отношения [Самсонов, 2015]. Часть этих структур теряет свое значение, другая часть видоизменяется, трансформируясь. (Например, сектор личных подсобных хозяйств населения, выступающий «первичным элемен- 
том» сельской неформальной экономики, производившие в начале 2000-х г. более половины товарного мяса, сейчас снизили этот показатель ниже «дореформенных» («советских») значений; углубление социально-экономической дифференциации сельского социума в последнее десятилетие привело к существенному сокращению интенсивности межсемейных обменов (свертыванию социальных сетей) и т. п.)

Динамичный рост и последующее стремительное сокращение значимости неформально-интегративных структур свидетельствуют о том, что мы имеем дело с определенным приспособительным (адаптивным) феноменом, зависящим, как любая адаптация, от сочетания внешних условий-вызовов и ресурсов, доступных адаптанту, практический выбор стратегий и практик действия которого ограничен кругозором его жизненного мира, наличием образцов инновационного поведения, или наоборот, традиционных паттернов, культурных норм, с одной стороны, структурирующих поле неформальных взаимодействий, а с другой - обеспечивающих некоторую надежность деятельности, разворачивающейся вне правового регулирования. Можно предположить, что институты определяют выбор траектории (на индивидуальном уровне - смену адаптационных, жизненных стратегий), а устойчивой «колеей» ее делает культура.

Гипертрофированное развитие неформальных практик и отношений в 1990-е гг., лежащих в основе сельской самоорганизации в России, было вызвано как особенностями адаптации сельского населения к рынку (вынужденного, вследствие сокращения возможностей официальной занятости, искать новые каналы социально-экономической активности), так и ослаблением государственного контроля в различных сферах общественной жизни в период масштабной перестройки, отсутствием детальной законодательной базы, адекватной изменившимся реалиям. Вслед за общим «упорядочением» социальной (и институциональной) среды происходит упадок неформальных структур. Также и развитие бартерной экономики в России во время периода острого финансового кризиса 1990-х гг. положило начало сложным и широким неформальным правилам обмена. Неписаные бартерные правила существовали и в предыдущей, советской системе, но постсоветская бартерная экономика и ее специфические правила представляли собой подлинную новацию, особенно потому, что новые неформальные отношения сформировались в сложную систему в краткий (и в конечном счете преходящий) исторический период. 
Наблюдения, подобные вышеприведенным, заставили некоторых исследователей подчеркнуть важность правовых рамок, адекватного регулирования и реализации формальных правил [Sachs, Pistor, 1997] - так как период преобразований продемонстрировал неустойчивость формальных правил, своего рода транзитной аномии. Характеризуя реформируемую Польшу, П. Штомпка писал: «Общее настроение неуверенности происходит также из-за нормативной дезорганизации или аномии. Правовая система - фрагментированная мозаика норм и инструкций, старых и новых, часто непоследовательных, неоднократно измененных, и произвольно интерпретируемых... противоречивая интерпретация законов делает их непостижимыми. Парламент обсуждает двадцать семь проектов новой конституция, а старая - путаница специальных поправок. Верховенство закона поставлено под угрозу экстра-юридическими решениями самых высоких властей, включая канцелярию президента.... Вера в непрерывность, стабильность и упорядоченность общественной жизни подорвана» [Sztompka, 1999. P. 77].

Помимо транзитной аномии кризисно-конфликтный характер развития постсоветских обществ обусловлен не-когерентностью институциональной среды в период преобразований, ведущей к дисбалансам в трансформации различных сфер общества, неравномерным темпам реформирования различных сфер социума, усиливающей «разницу социального времени» культурно-экономических центров и периферии. Так, приоритетное внимание реформированию экономики в 1990-е гг. в России, сопровождавшееся инерционными показателями развития системы государственных институтов и массовых ценностей россиян (с приоритетом пассивно-реактивной адаптации), привело к обострению кризисных явлений в первую очередь в сфере экономики (кризис 1998 г.). Приоритетное внимание руководства Украины, отдаваемое вопросам нациестроительства, и усилия, направленные на решение очевидно невыполнимых задач по достижению культурной однородности, наряду с отсутствием существенного развития в других сферах - закономерно (с точки зрения необходимости согласованного и одновременного внедрения новаций в ткань общества) привели к масштабному этнически-культурному конфликту современности.

\section{Список литературы}

Грановеттер М. Экономические институты как социальные конструкты: рамки анализа // Журнал социологии и социальной антропологии. 2004. Т. 7, № 1. С. 76-89. 
Самсонов В. В. Неформальный сектор сельской России и его динамика // Сиб. филос. журн. 2015. Т. 13, № 3. С. 119-129.

Hall J. A. Civil Society. Theory, History, Comparison. Cambridge: Polity, 1996.

Kuzio T. Transition in Post-Communist States: Triple or Quadruple? // Politics. 2001. Vol. 21(3). P. 168-177.

Linz J. J., Stepan A. Problems of Democratic Transition and Consolidation // Southern Europe, South America and Post-Communist Europe. Baltimore: Johns Hopkins Univ. Press, 1996.

Pejovich S. Understanding the Transaction Costs of Transition: It's the Culture, Stupid! // Review of Austrian Economics. 2003. No. 16. P. 361-374.

Sachs J., Pistor K. The Rule of Eaw and Economic Reform in Russia. Boulder (Co.), Westview Press, 1997.

Stark D. Path Dependence and Privatization Strategies in East Central Europe // East European Politics and Societies. 1992. Vol. 6. No. 1. P. 17-54. Sztompka P. Trust: A Sociological Theory. Cambridge: Cambridge Univ. Press, 1999.

Материал поступил в редколлегию 29.09.2018

\section{V. Samsonov}

Institute of Philosophy and Law SB RAS

8 Nikolaev Str., Novosibirsk, 630090, Russian Federation

highbook@yandex.ru

\section{INSTITUTIONAL AND SOCIO-CULTURAL FACTORS OF POST- SOCIALIST TRANSFORMATIONS}

The paper studies the logic of the development of the theory of postsocialist transit under the influence of the practice of transformations in various countries of the former "socialist camp», which showed the need for a more differentiated doctrine of analysis. It also treats the problem of the correlation of institutional and sociocultural transformation factors. While in modern studies of the reasons for path dependence, authors increasingly pay attention to cultural factors, a practical analysis of the development of post-socialist societies in the context of the most important institutional changes demonstrates surprising dynamics, which is rather a rational reactive response to momentary changes in institutional conditions. This gives grounds to assume that the institutions determine the choice of the 
trajectory of development (at the individual level - the change of adaptive, life strategies), and culture makes a stable «path».

Keywords: transformation, post-socialist transit, institutional and sociocultural factors, economic reforms.

\section{References}

Granovetter M. Ekonomicheskie instituty kak social'nye konstrukty: ramki analiza [Economic Institutions as Social Constructs: Framework for Analysis]. Journal of Sociology and Social Anthropology, 2004, vol. 7, no 1, p. 76-89. (In Russ.)

Hall J. A. Civil Society. Theory, History, Comparison, Cambridge, Polity, 1996.

Kuzio T. Transition in Post-Communist States: Triple or Quadruple? Politics, 2001, vol. 21 (3), p. 168-177.

Linz J. J., Stepan A. Problems of Democratic Transition and Consolidation. Southern Europe, South America and Post-Communist Europe. Baltimore, Johns Hopkins Univ. Press, 1996.

Pejovich S. Understanding the Transaction Costs of Transition: It's the Culture, Stupid! Review of Austrian Economics, 2003, no. 16, p. 361-374.

Sachs J., Pistor K. The Rule of Eaw and Economic Reform in Russia. Boulder (Co.), Westview Press, 1997.

Samsonov V. V. Neformalnyi sektor selskoi Rossii i ego dinamika [Informal sector of rural Russia and its dynamics]. Siberian Journal of Philosophy, 2015, vol. 13, no 3, p. 119-129. (In Russ.)

Stark D. Path Dependence and Privatization Strategies in East Central Europe. East European Politics and Societies, 1992, vol. 6, no. 1, p. 17-54.

Sztompka P. Trust: A Sociological Theory. Cambridge, Cambridge University Press, 1999. 